\title{
O IMPACTO DA ALFABETIZAÇÃO VISUAL PARANISTA RESPONDENDO AO IDEAL-REPUBLICANO [ ${ }^{1}$
}

\author{
Sandra Makowiecky[ $\left.{ }^{2}\right]$ \\ Luciana Estevam Barone Bueno $\left[{ }^{3}\right]$
}

RESUMO: Este artigo trata de um possível resgate do momento em que intelectuais curitibanos (Movimento Paranista) se unem ao Movimento Simbolista para criar uma “iconologia-forjada" para o Estado do Paraná. Estimulados talvez pelo fato de o Estado do Paraná não possuir traços próprios regionais específicos, inventam uma tradição respondendo ainda aos ideais republicanos de aspirações modernizantes, tendo como principal estratégia a recorrência às artes plásticas.

PALAVRAS-CHAVE: Imaginário-popular, Iconologia-forjada, Paranismo, Idealrepublicano.

No contexto da Proclamação da República, o Paraná ergueu a bandeira de um republicanismo positiva e anti-clerical, posicionamento que foi endossado principalmente pela produção literária de caráter simbolista. O Movimento Simbolista mesmo com representantes em outros estados, no Paraná, teve uma atuação singular e original. Segundo Marcio Oliveira:

(...) O Simbolismo, embora tendo representantes em vários estados, foi
especialmente vigoroso no Paraná e, por conseguinte, é descrito como um
simbolismo particular. A primeira particularidade (estendida ao próprio estado)
liga-se ao clima da cidade de Curitiba, considerado frio e europeu, e ao relevo
ondulado de suas montanhas, o que aproximaria os escritores locais do "clima" da
matriz simbolista parisiense. (OLIVEIRA, 2007)

Bastide (1980), afirma que a particularidade do Simbolismo no Paraná bem como no Sul, é extremamente relacionada ao clima bem específico e diferenciado de outros Estados brasileiros:

\footnotetext{
${ }^{1}$ Este artigo se baseia nos trabalhos realizados de pesquisa de mestrado junto a Universidade do Estado de Santa Catarina no programa de Pós-Graduação em Artes Visuais - Mestrado, na linha de pesquisa "Teoria e História das Artes Visuais".

${ }^{2}$ Professora do PPGAV, CEART - UDESC, orientadora.

${ }^{3}$ Aluna regularmente matriculada no PPGAV, CEART - UDESC
}

DAPesquisa, Florianópolis, v.3 n.5, p.216-224, 2008. 
"O Simbolismo do Paraná é também a primeira manifestação de um "Brasil diferente" contra o Brasil tropical, uma tomada de consciência literária do que o Paraná apresenta de específico, mas também de autenticamente brasileiro, contra os que querem modelar todos os brasileiros segundo um mesmo padrão: clima temperado contra sol tórrido, bruma esbranquiçada e geada, minuano gelado do Sul, contra os alísios, os pomares em flores e florestas virgens". (BASTIDE, 1980 p 212).

A grande projeção do Movimento Simbolista de vertente neo-pitagórica, no Paraná republicano, ocorreu devido à convergência deste movimento com a aura construída pela República, no que tange à ciência e ao ensino laico. A ciência e o ensino laico foram considerados elementos modernizantes da sociedade, em oposição a uma visão mística do mundo dada pela Igreja Católica, fato que foi considerado pelos anti-clericais como uma das falências do regime monárquico.

Outra aspiração modernizante que surgiu no Paraná na década de vinte, expressou-se a partir de uma reflexão da intelectualidade curitibana sobre o fato do Paraná não possuir traços específicos regionais por meio de lendas, tradições e vultos históricos. A inexistência destes traços regionais foi apontada pelos intelectuais como resquícios de descaso do regime monárquico com o Estado. Baseando-se nestas reflexões, a intelectualidade curitibana resolveu criar o Movimento Paranista a fim de forjar a identidade paranaense.

Definido nominalmente em 1927, “O Paranismo", este movimento que reuniu intelectuais curitibanos aliados ao grupo de simbolistas, começa a pensar num discurso histórico e um processo de formulação de uma imagem para o Estado do Paraná, um pensamento que se inicia com a emancipação política, ocorrida em 1853.

Brasil Pinheiro Machado, em uma publicação no ano de 1930, num dos Instantâneos Paranaenses - A Ordem - afirma: “O Paraná é um estado típico desses que não tem um traço que faça deles alguma coisa notável”. Era preciso então, criar uma tradição para este Estado forjando uma historiografia, o que Eric Hobsbawm chamou de Invenção das Tradições:

Por tradição inventada entende-se um conjunto de práticas, normalmente reguladas por regras tácita ou abertamente aceitas; tais práticas, de natureza ritual ou simbólica, visam inculcar certos valores e normas de comportamento através da repetição o que implica automaticamente, uma continuidade em relação ao passado. Aliás, sempre que possível, tenta-se estabelecer continuidade com um passado histórico apropriado. (HOBSBAWM, 1984, p.09) 
Aproveitando o surto econômico positivo da erva-mate, da exportação de café, da exportação da madeira e da implantação de fábricas, os paranistas aguçaram o desejo de construir uma história regional que mostrasse o Paraná como um local que possuía uma tradição e uma história, os paranistas realmente tinham a intenção de inventar uma tradição para um Estado sem características. Revestido de um caráter de antiguidade, o discurso histórico dos paranistas tinha uma aura ligada às instituições republicanas, onde acreditavam que o imaginário popular carecia de retorno às antiguidades. SegundoPereira:

O passado construído pelos paranistas, como não podia deixar de ser, privilegiava a história política encontrada nos documentos oficiais, tentando impor tal visão ao presente que seria, necessariamente fruto de uma continuidade com este passado glorioso e, criando estereótipos e fabricando heróis, com grandes personagens históricos, legam um exemplo à população. (PEREIRA, 1998, p. 93)

José Murilo de Carvalho, em seu livro A Formação das Almas, ao falar sobre os ideais republicanos afirma que, para operar um extravasamento de república no mundo extra-elite, seria necessário outras tentativas, além do discurso: “(...) não poderia ser feito por meio do discurso, inacessível a um público com baixo nível de educação formal. Ele teria de ser feito mediante sinais universais, de leitura mais fácil, como as imagens, as alegorias, os símbolos, os mitos." (CARVALHO, 2005, p.13-14). Assim sendo, o principal recurso do Movimento Paranista para atingir o "Imaginário-popular" foi utilizar-se das artes plásticas, propondo uma alfabetização visual não formal, ou seja, não escolar. A recorrência às artes plásticas foi a grande estratégia paranista de construir, no imaginário paranaense, a idéia de progresso e ciência.

Entre símbolos e representações, o ideário regional foi o que produziu a aura de afeições da população às terras paranaenses, bem como, a construção do tipo ideal paranista - o paranaense - que até então não se havia consolidado. Muitos dos intelectuais, bem como alguns artistas que faziam parte do grupo e estavam atuantes nas reuniões paranistas, não eram paranaenses (nascidos no Paraná), outros sequer, eram nascidos no Brasil. Era necessário, portanto, adotar uma terminologia que abarcasse também o imigrante, foi então, que Romário Martins publicou um artigo explicando a significação do termo Paranista:

Paranista é todo aquele que tem pelo Paraná uma afeição sincera, e que notavelmente a demonstra em qualquer manifestação de atividade digna, útil à coletividade paranaense. (...) Paranista é aquele que em terras do Paraná lavrou 
um campo, cadeou uma floresta, lançou uma ponte, construiu uma máquina, dirigiu uma fábrica, compôs uma estrofe, pintou um quadro, esculpiu uma estátua, redigiu uma lei liberal, praticou a bondade, iluminou um cérebro, evitou uma injustiça, educou um sentimento, reformou um perverso, escreveu um livro, plantou uma árvore (MARTINS, 1946, p.91).

Os símbolos que serviam para a identificação emblemática do Paraná giraram em torno das imagens do pinheiro, da pinha e do pinhão. Lange de Morretes, artista plástico, ao descrever sobre a idéia de como chegaram à estilização do pinheiro (símbolo do movimento), deixa explícito que estava no ateliê de João Ghelfi juntamente com João Turim, também artistas plásticos. Suas palavras expressaram desta maneira:

[...] Quando um artista paranaense está só ele pensa no pinheiro; quando está em companhia de outro artista, fala do pinheiro; e quando os artistas reunidos são mais de dois, discutem sobre o pinheiro. Não era pois de se estranhar a conversa ter se encaminhado para o pinheiro. Discutíamos as suas qualidades, as suas dificuldades e as suas novas possibilidades para o campo da arte. Ghelfi, sempre, entusiasmado e sonhador, tomou de um pedaço de carvão e na parede de seu atelier traçou, do tronco do pinheiro, um fragmento de fuste, sobre o qual compôs um grupo de pinhas como capitel." Lange de Morretes continua sua descrição intitulando Ghelfi como um semeador (...) "Depois cada um para sua casa, com um pinheiro na cabeça envolto na bruma do chope. Turin e eu estávamos com uma semente no peito a germinar. E, curioso, o semeador Ghelfi contentou-se com a semeadura. Talvez, devido a sua morte prematura (...) Há sementes que não brotam ao cair da primeira chuva. Levam tempo. Assim a estilização do pinheiro não nascera da noite para o dia. Turin matutou muito, eu não menos. [...] (MORRETES, In Revista Ilustração Brasileira, dez 1953).

Neste relato, Lange de Morretes nos alerta sobre a participação de João Guelfi como sendo essencial e marcante dentro do movimento paranista. Este artista foi considerado dentre os demais, -um semeador, sua função dentro do grupo foi lançar a semente, a vida não lhe deu oportunidade de vê-la crescer, provavelmente, continuaria atuante se não fosse sua morte repentina. Portanto, os artistas plásticos reconhecidos como responsáveis pela divulgação artística do Movimento Paranista, foram João Turin, Zaco Paraná e Lange de Morretes, estes, empenharam-se em produzir obras com os símbolos, denominados paranistas.

Tais obras, visualmente retornavam ao passado, em inspirações clássicas, como que reforçando o discurso de que a antiguidade seria o melhor alicerce para a identidade que estava sendo criada. Em relação ao retorno às obras consagradas, Rodrigo Naves (2007) afirma, "Acredito que num momento confuso e turbulento o retorno às melhores obras tem mais a ensinar do que o apego a idéias apenas aparentemente confiáveis. Quando 
se está perdido, mais valem os vagos contornos da intuição do que o norte claro de parte alguma" (NAVES, 2007, p. 28)

O escultor João Turin, inspirando-se na coluna grega "criou" a coluna paranista adornada com as pinhas e pinhões, que seriam característicos do movimento. ( Imagem 1).
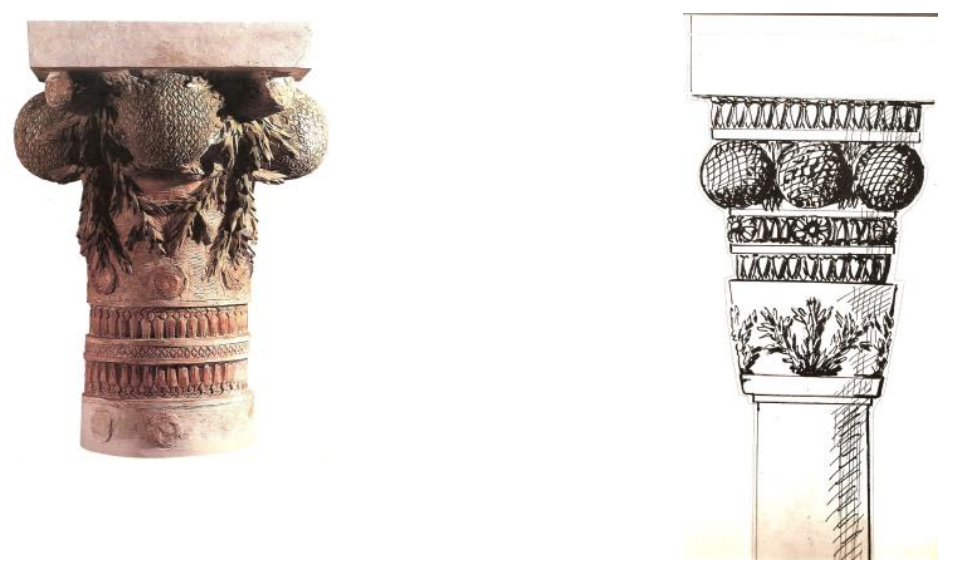

Imagem 1- Colunas Paranistas: João Turin - Fonte: Elisabete Turin, 1998.

Segundo Irã Dudeque, em seu livro Espirais de Madeira - Uma História da Arquitetura de Curitiba, o que João Jurin fez, foi utilizar o princípio de Roberto Lacombe metamorfoseando as ordens clássicas arquitetônicas com adaptações nas proporções do pinheiro. O autor faz uma citação extraída da Revista Ilustração Paranaense, na qual, a referida coluna é apresentada como sendo da ordem paranaense, "A estylisação paranaense: fragmentos inspirados em nossos magestosos e imponentes pinheiros". Dudeque afirma que a construção partiu do desenvolvimento da ordem jônica com simplificações do pinheiro e adaptações encaixadas nas "receitas corriqueiras dos estilos arquitetônicos”. O autor segue ainda dizendo que poucas eram as regras de construção e, que o escultor João Turin não apresentou todas as proporções, o artista apenas registrou que:

[...] a coluna paranaense não deveria ser excessivamente esbelta e nem teria entablamentos, pois o tronco do pinheiro brota diretamente do solo. O capitel seria formado por pinhas e pinhões inscrustados, que também poderiam se espalhar em guirlandas.(BLOCH In DUDEQUE, 2001, p.62).

Dudeque nos alerta que muitos artistas renascentistas e barrocos utilizaram as origens vegetais das colunas clássicas e que o Paraná ao criar sua própria ordem estaria 
ligado "às mais remotas gêneses da arquitetura e da arte”. Segue ainda o autor, dizendo que:

Tal ordem apontava para a grandeza da terra paranaense, uma força a mais para a grandeza da terra brasileira, o que ampliaria a grandeza da arquitetura universal. E não só. Com a ordem paranaense, o Paraná poderia atingir uma expressão própria na arquitetura moderna [...]) Tal definição pode parecer uma aberração depois que o adjetivo moderno foi encapado pela arquitetura derivada das vanguardas européias daquela mesma década de 1920. (DUDEQUE, 2001 p.62)

Para Irã Dudeque, a idéia de se criar uma diferenciação para o Paraná, era na verdade uma necessidade de mostrar que este Estado tinha uma cultura, um símbolo. Para este autor Paranismo seria,

(...) uma tentativa de criar um símbolo que identificasse todos os homens do Paraná. Que símbolo seria esse? Nós não temos um grande literato, nós não temos uma grande data, nós não temos uma grande história, nós não temos um grande poeta como Castro Alves, nós não temos um grande literato como José de Alencar. O que nos sobra? Sobra a natureza, quer dizer, é um discurso que acaba sendo muito triste no sentido de que só nos tenha sobrado uma árvore e que ao longo das décadas nos coubesse cultuar essa árvore e reverenciá-la. (DUDEQUE, 2005, p.52).

O pinheiro esteve presente na maior parte da produção artística dos artistas que viviam no Paraná desde a década de 20 ou 30, quando o Paranismo teve sua ascensão, continuou presente nas obras de artistas que surgiram posteriormente ao movimento e continua marcando presença em obras de alguns artistas que atualmente vivem no Estado. Segundo Pereira, a representação pictórica do pinheiro e de seus frutos foi tão forte que ultrapassou as telas dos quadros e ganhou as ruas curitibanas e paranaenses, aparecendo na estilização simbólica das calçadas, iluminarias públicas, pilares, etc.

Lange de Morretes foi o responsável pela estilização do pinheiro, da pinha e do pinhão utilizados como adornos decorativos em toda Capital do Estado. Ele também fez de sua vida uma entrega aos pensamentos e ideais paranistas, produziu suas obras com verdadeira fidelidade ao pinheiro, deixando recomendado que após sua morte “(...) queria ser enterrado em pé e com o rosto virado para o Pico do Marumbi, em terreno de um metro quadrado que comprara em Morretes a fim de lhe servir de sepultura”.(PEREIRA, 1998 p. 147).

Zaco Paraná, escultor, além de participar ativamente do movimento, deixou pela cidade muitas obras que retornam aos ideais e pensamentos paranistas. É dele, a obra "O Semeador", encomenda feita pela colônia polonesa no Paraná, em comemoração ao 
centenário da Independência, inaugurada somente em 1925. O trabalho que, na verdade, não se trata de uma obra paranista, além de ter sido produzida antes da consolidação do movimento, não possui no sentido estilístico absolutamente nada de paranista. Nela, não há características de pinha, pinhão ou pinheiro. Porém, a estátua do semeador aparece em imagens mostrando os monumentos de Curitiba, como símbolos de modernidade. Na revista "Ilustração Paranaense", a obra é colocada junto a outros monumentos de aspirações modernizantes, incluindo um relato sobre Zaco Paraná e a execução de "O Semeador".

O Semeador foi incorporado pelos Paranistas, como uma prova da existência de uma arte simbólica antes do Paranismo propriamente dito. Para Pereira, "Esta obra, mais do que o pinheiro, reúne em si todas as características pretendidas pelo Movimento Paranista”. Segundo o mesmo autor, a obra feita para representar a Colônia Polonesa

\footnotetext{
(...) passa com o tempo a ser identificado como o grande herói paranista, que semeia o Paraná do futuro e deixa no Paraná a sua marca. (...) Uma das grandes vantagens desta figura era o fato de que o mesmo pode ser qualquer um, qualquer pessoa que se enquadre na caracterização de paranista, ou seja, aquele que semeia a cultura, as artes, o solo, as fábricas, todos aqueles que deixam a sua semente para a construção de um Paraná melhor. (PEREIRA,1998 p 157).
}

Hoje, os símbolos continuam presentes maciçamente na Capital do Estado, fazendo parte de um cenário comum, porém, a maioria das pessoas que pisam nos petit pavês com formas de pinhões estilizados por Lange de Morretes, não faz idéia do que há por trás destas produções e desconhecem sua história. Apesar do movimento paranista se restringir à Curitiba, os paranaenses em geral reconhecem a pinha, o pinheiro e o pinhão como seus símbolos, mesmo não sabendo a razão de ser o "Pinheiro" a árvore que representa o Paraná, tendo em vista que em outros Estados esta árvore também é encontrada.

Podemos então pensar que, os paranistas mesmo forjando uma identidade com estes símbolos, conseguiram fazer com que hoje os paranaenses os reconhecessem como parte de sua identidade, a "possível identidade paranaense”. Porém, podemos ainda pensar se realmente o Paraná tem alguma identidade definida, mesmo sabendo que, este não é um problema só deste Estado, existem algumas histórias comuns a respeito deste assunto. Dudeque (2005, p.50 - 68) ao falar sobre o Barroco Mineiro, enfatiza que alguns autores 
dizem que ele não existe e o que realmente existe é o Barroco Colonial. “(...) Isso é importante porque, se não houver identidade, uma identidade arquitetônica que possa nos diferenciar, também não há alguma coisa vergonhosa. Não temos identidade porque no fundo ninguém tem”. (2005, p.56). O autor acaba chegando à conclusão de que, se não há identidade, o que nos resta é a memória.

O que realmente podemos considerar é que a arte cumpriu com uma tarefa extremamente importante. Foi através das artes plásticas, da alfabetização visual imposta pelos paranistas que os corações paranaenses foram atingidos e sensibilizados. Segundo Pereira,

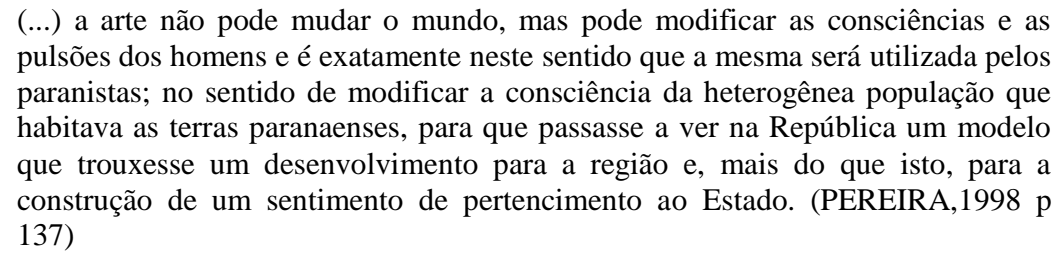

(...) a arte não pode mudar o mundo, mas pode modificar as consciências e as pulsões dos homens e é exatamente neste sentido que a mesma será utilizada pelos paranistas; no sentido de modificar a consciência da heterogênea população que habitava as terras paranaenses, para que passasse a ver na República um modelo que trouxesse um desenvolvimento para a região e, mais do que isto, para a construção de um sentimento de pertencimento ao Estado. (PEREIRA,1998 p 137)

Mesmo sendo a produção artística considerada muitas vezes não uma arte paranista e sim um estilo, foi através dela que esta tentativa de construção de uma identidade regional no Paraná se concretizou. Os paranistas tiveram apenas a preocupação de construir obras que tivessem um elo perfeito com o imaginário popular da época, estabelecendo assim uma sintonia entre os símbolos criados pela elite curitibana, ou seja, pelos intelectuais da época e a população que os acolheu.

\section{REFERÊNCIAS BIBLIOGRÁFICAS}

BASTIDE, Roger. Brasil, terra de contrastes. Rio de Janeiro, São Paulo: Difel, 10a ed. 1980 p. 212

CARVALHO, José Murilo de. A formação das almas: o imaginário da República no Brasil. $15^{\mathrm{a}}$. ed. São Paulo: Companhia das Letras, 2005, p. 13-14. (1 ${ }^{\mathrm{a}}$. ed. 1990)

DUDEQUE, Irã Taborda. Espirais de madeira - uma história da arquitetura de Curitiba. São Paulo: Estúdio Nobel: FAPESP, 2001, p.62

DUDEQUE, Irã Taborda. In: Simpósio de Cultura Paranaense - Terra, Cultura e Poder: A Arqueologia de um Estado, 1 a 5 de dezembro de 2003. - Curitiba: Sec. de Estado da Cultura, 2005, 170 p.50 - 52-56- 68 
HOBSBAWM, Eric J. \& RANGER, Terence. Invenção das tradições. Rio de Janeiro: Paz e Terra, 1984. p 09

MARTINS, Romário. Paranística. In A divulgação. Curitiba. Fev-mar. 1946, p.91.

MORRETES, Lange de. O pinheiro na arte. Curitiba: In: Revista Ilustração Brasileira, dez, 1953.

NAVES, Rodrigo. O Vento e o moinho: ensaios sobre arte moderna e contemporânea. São Paulo: Companhia das Letras, 2007.p28

OLIVEIRA, Márcio de «Imigração e diferença em um estado do sul do Brasil: o caso do Paraná», Nuevo Mundo Mundos Nuevos, Debates, 2007, [En línea], Puesto en línea el 18 mai 2007. URL: http://nuevomundo.revues.org//index5287.html. Consultado el 10 juillet 2008.

PEREIRA, Luis Fernando Lopes, Paranismo: O Paraná Inventado; cultura e imaginário no Paraná da I República. Curitiba: Aos quatro ventos, 1998. p 93 -137 - 147 -157

TURIN, Elizabete. A arte de João Turin. Campo Largo, PR: INGRA, 1998. 